\title{
Insidens Kandidemia di Paediatric Intensive Care Unit Rumah Sakit Dr. Cipto Mangunkusumo
}

I Gde Doddy Kurnia Indrawan, ${ }^{*}$ Antonius H Pudjiadi, ${ }^{* *}$ Abdul Latief**

*SMF Ilmu Kesehatan Anak RSUD Wangaya, ${ }^{* *}$ Departemen Ilmu Kesehatan Anak Fakultas Kedokteran Universitas Indonesia

Latar belakang. Kandidemia menjadi salah satu masalah di PICU, angka kejadiannya meningkat setiap tahun dengan angka kematian yang tinggi, serta memperpanjang masa rawat di rumah sakit. Sampai saat ini, data insidens kandidemia pada anak masih terbatas. Tujuan. Mengetahui insidens kandidemia di PICU RSCM.

Metode. Penelitian retrospektif dilakukan di RS Cipto Mangunkusumo dengan mencatat data rekam medis pasien kandidemia pada anak periode 1 Januari 2013 sampai 31 Desember 2014.

Hasil. Didapatkan 32 kejadian kandidemia dalam kurun waktu pengambilan data. Median usia pasien 12,8 bulan, 57,7\% berjenis kelamin laki-laki. Sebagian besar pasien mengalami gizi kurang, 69,2\% kasus bedah dan 30,8\% non bedah. Penggunaan steroid 11,5\%. Selama perawatan di PICU, 96,2\% pasien menggunakan ETT, 100\% menggunakan kateter vena sentral dan kateter urin. Pasien yang menggunakan antibiotik $>15$ hari $80,8 \%$. Median skor awal PELOD adalah 12 . Median waktu pemberian anti jamur 15,8 hari perawatan di PICU, luaran hidup 65,4\%, rerata lama rawat PICU 25,8 hari. Penyakit yang mendasari perawatan di PICU 7,7\% infeksi saluran pernapasan, 3,8\% infeksi sistem saraf, 19,2\% syok sepsis, 3,8\% pascabedah kepala leher, 11,5\% pasca bedah dada, dan 53,8 pasca bedah abdomen. Rerata lama pemggunaan ETT 10,04 hari, kateter vena sentral 15,65 hari, dan kateter urin 11,15 hari. Jenis kandida terbanyak adalah kandida parapsilosis. Lebih dari dua antibiotik diberikan pada $76,8 \%$ pasien sebelum mendapatkan anti jamur.

Kesimpulan. Kejadian kandidemia serupa dengan negara berkembang lainnya dan ditemukan meningkat pada pasien dengan status gizi kurang, pasacabedah, penggunaan alat medis invasif, dan penggunaa antibiotik >15 hari. Sari Pediatri 2016;18(3):182-6

Kata kunci: kandidemia, insidens, PICU

\section{Incidence of Candidemia in Paediatric Intensive Care Unit in Dr. Cipto Mangunkusumo Hospital}

I Gde Doddy Kurnia Indrawan, Antonius H Pudjiadi, Abdul Latief

Background. Candidemia has become an important problem in PICU because the incidence has dramatically increased every year and with a high mortality rate as well as high health care costs. To date incidence data in children is limited.

Objective. To know the incidence of candidemia in PICU RSCM.

Methods. A retrospective study was conducted in Cipto Mangunkusuomo general hospital with medical record data recorded diagnosis of septic shock in children period from 1 january 2013 to December 31, 2014.

Results. A total of 32 candidemia events in the period of data collection. The median age of patients was 12.8 months, $57.7 \%$ male sex. Nutritional status of patients some of which have mild malnutrition. There were $69.2 \%$ was the case surgery and $30.8 \%$ of patients non surgery.Using of steroid was 11.5\%.At the treatment in PICU, $96.2 \%$ of patients used ett, $100 \%$ of patients used catheter vein central and catheter urin. Patients that received antibiotics $>15$ days was $80.8 \%$. The median initial PELOD day care in the PICU was 12.Patients received antifungal when 15.8 days care in the PICU. The outer covering of life is $65.4 \%$ and die $34.6 \%$. Lenght of PICU stays was25,8 days. The underlying diseases that required PICU were $7.7 \%$ respiratory infection, 3.8\%, neurology infection, $19.2 \%$ septic shock, $3.8 \%$ post head and neck surgery, $11.5 \%$ post thorac surgery, and 53.8 post abdomen surgery. Rate length of using ETT was 10.04 days, CVC 15.65 days, urine catheter 11.15 days. The most isolated candida from blood culture was candida parapsilosis. There was $76.8 \%$ received $>2$ antibiotics before antifungal injection.

Conclusion. The incidens of candidemia was similar with other developing countries and found increased in patients with characteristic mild malnutrition, post surgical,using invasive medic al devices, and using antibiotics >15 days. Sari Pediatri 2016;18(3):182-6

Keywords: candidemia, epidemiology, PICU

Alamat korespodensi: Dr. I Gde Doddy Kurnia Indrawan, MSc, SpA(K). SMF Ilmu Kesehatan Anak RSUD Wangaya Kota Denpasar Jl Kartini Denpasar Bali. E-mail: doddy_kurnia90@yahoo.com 
K andidemia merupakan infeksi jamur sistemik yang disebabkan kandida spesies yang bisa terjadi pada pasien sakit kritis Lyang dirawat di ruang rawat intensif. Infeksi jamur sistemik menjadi salah satu masalah dalam ruang intensif di negara berkembang dan negara maju. Kejadian kandidemia pada anak yang dirawat di PICU cukup tinggi dan meningkat dalam masa dua dekade ini. Peningkatan berkisar antara 2,3-4 kali setiap dekade, dan cenderung meningkat pada anak berusia kurang dari 2 tahun, tetapi tidak berhubungan dengan jenis kelamin. Di Amerika Serikat, kandidemia mempunyai angka kejadian 101 kasus dari 1000 pasien yang dirawat di RS Anak Philadelphia. Hegazi dkk ${ }^{1}$ melaporkan kejadian kandidemia di PICU 19\% (66/347 pasien yang dirawat di PICU). Penelitian di India melaporkan insiden kandidemia $8,1 \%$ pada pasien anak sakit kirtis. ${ }^{2}$

Secara epidemiologi, Candida albicans merupakan spesies kandida terbanyak sebagai penyebab kandidemia Terdapat pula kandida lainnya, yaitu Candida parapsilosis, Candida tropikalis, Candida glabrata, dan Candida krusei. Semua penyakit yang mendasari pasien masuk PICU dapat berkembang menjadi kandidemia karena dipengaruhi faktor risiko, seperti penggunaan antibiotik yang lama (lebih dari 15 hari) dan spektrum luas antibiotik, penggunaan endotrakheal tube (ETT), pembedahan, penggunaan kateter vena sentral, kateter urin, dan steroid. Pasien yang mengalami kandidemia mempunyai angka kematian tinggi. Di samping itu, kandidemia dapat memperpanjang masa rawat inap dan meningkatkan penggunaan alat penunjang rawat sehingga biaya meningkat. ${ }^{1-3}$

Sampai saat ini, data mengenai kandidemia di PICU seperti angka kejadian, karakteristik pasien dengan kandidemia, dan luarannya masih terbatas. Studi ini bertujuan mengetahui epidemiologi kandidemia di PICU RSCM.

\section{Metode}

Studi cross sectional yang dilakukan di RSUP Cipto Mangunkusumo, Jakarta. Data diambil dari rekam medis pasien anak usia 1 bulan sampai 18 tahun dengan kandidemia sebagai diagnosis utama pada kurun waktu masuk rumah sakit antara 1 Desember 2013- 1 Januari 2014. Data diambil dari rekam medis, dilakukan pencatatan nama, nomor rekam medik, tanggal masuk PICU, diagnosis masuk PICU, usia, jenis kelamin, status gizi, penggunaan kortikosteroid, penggunaan alat medis invasif, penggunaan antibiotik, skor PELOD, luaran, dan lama rawat. Kriteria inklusi adalah status pasien berusia 1 bulan -18 tahun yang dirawat di PICU dengan dokumentasi lengkap yang berisi data usia, jenis kelamin, status gizi, penggunaan kortikosteroid, penggunaan alat medis invasif, penggunaan antibiotik, skor PELOD, waktu pemberian anti jamur, luaran, dan lama rawat, gambaran lama penggunaan alat medis invasif, jenis kandida, jumlah penggunaan antibiotik. Kriteria eksklusi apabila data rekam medik tidak lengkap.

Analisis data menggunakan program komputer SPSS versi 20. Analisis deskriptif terhadap variabeldalam penelitian ini, dihitung distribusi frekuensi, rerata atau median (berdasar uji Shapiro- Wilk), dan proporsi.

\section{Hasil}

Kejadian kandidemia dijumpai pada 8,3\% (32/385 subyek). Penyakit yang mendasari saat masuk PICU tertera pada Tabel 2. Pasca bedah abdomen mempunyai jumlah tertinggi saat masuk PICU (53,8\%), sedangkan pasien bukan bedah yang terbanyak adalah pasien syok sepsis $(19,2 \%)$.

Lama penggunaan ETT, kateter vena sentral, dan kateter urin tertera pada Tabel 3. Pada penelitian ini didapatkan rerata lama penggunaan ETT 10,0 hari, lama penggunaan vena 15,65 hari, dan rerata penggunaan kateter urin 11,53 hari. Jenis kandida terbanyak Candida parapsilosis 46,2\%, diikuti oleh Candida tropikalis 38,5\%, sedangkan Candida albicans masing-masing $7,7 \%$.

\section{Pembahasan}

Kandidemia sering terjadi pada pasien anak yang dirawat di PICU. Kami mendapatkan kejadian kandidemia $8,3 \%$, hampir sama dengan penelitian di India yang melaporkan insiden kandidemia 8,1\% pada pasien anak sakit kirtis. ${ }^{4}$ Pada penelitian kami, kejadian kandidemia lebih banyak terjadi pada laki-laki $(57,7 \%)$. Hasil serupa juga diperoleh Hegazi $\mathrm{dkk}^{5} \mathrm{dan}$ Singhi dkk, ${ }^{6}$ tetapi berbeda dengan Zaoutis dkk. ${ }^{7}$ Pada penelitian lain, jenis kelamin bukan merupakan faktor 
Tabel 1. Karakteristik subyek penelitian

\begin{tabular}{lc}
\hline Karakteristik & Jumlah (n=26) \\
\hline Jenis kelamin, n (\%) & \\
$\quad$ Laki-laki & $15(57,7)$ \\
Usia, rerata (SB) bulan & $12,8(4,4)$ \\
Status gizi, n (\%) & \\
$\quad$ Kurang & $19(73,1)$ \\
$\quad$ Cukup & $1(3,8)$ \\
$\quad$ Buruk & $6(23,1)$ \\
Jenis penyakit, bedah, n (\%) & $18(69,2)$ \\
Penggunaan kortikosteroid, n (\%) & $3(11,5)$ \\
Penggunaan alat medis invasif, n (\%) & \\
$\quad$ Endotrakheal tube & $25(96,2)$ \\
$\quad$ Kateter vena sentral & $26(100)$ \\
$\quad$ Kateter urin & $26(100)$ \\
Penggunaan antibiotik $>15$ hari, n (\%) & $21(80,8 \%)$ \\
Skor PELOD, median (min-maks) & $12(10,9-21,8)$ \\
Waktu pemberian antijamur, median (min-maks),hari & $15,8(8,9-19,5)$ \\
Luaran, n (\%) & \\
$\quad$ Mati & $9(34,6)$ \\
$\quad$ Lama rawat PICU, rerata (SB) hari & $25,8(6,0)$ \\
\hline
\end{tabular}

Tabel 2. Penyakit dasar saat masuk PICU

\begin{tabular}{lc}
\hline Variabel & Jumlah $(\mathrm{n}=26)$ \\
\hline Infeksi saluran napas, $\mathrm{n}(\%)$ & $2(7,7)$ \\
Infeksi sistem saraf, n (\%) & $1(3,8)$ \\
Syok sepsis, n (\%) & $5(19,2)$ \\
Pasca bedah kepala leher, n (\%) & $1(3,8)$ \\
Pasca bedah dada, $\mathrm{n}(\%)$ & $3(11,5)$ \\
Pasca bedah abdomen, $\mathrm{n}(\%)$ & $14(53,8)$ \\
\hline
\end{tabular}

Tabel 3. Lama penggunaan ETT, vena dalam, dan kateter urin

\begin{tabular}{lc}
\hline Variabel & Jumlah $(\mathrm{n}=26)$ \\
\hline Lama penggunaan ETT, rerata (SB) hari & $10,0(4,60)$ \\
Lama penggunaan kateter vena sentral, rerata (SB) hari & $15,6(2,98)$ \\
Lama penggunaan kateter urin, rerata (SB) hari & $11,1(3,88)$ \\
\hline
\end{tabular}

prediktor kandidemia. Rerata usia penelitian kami 12,8 bulan, sedangkan Hegazi $\mathrm{dkk}^{5}$ juga melaporkan rerata usia kandidemia adalah 12 bulan.

Respon stres sistemik pada anak sakit kritis di PICU dapat menekan mekanisme imunitas normal. Hal tersebut diperberat oleh malnutrisi dan berhubungan dengan peningkatan kejadian infeksi akibat imunitas yang rendah. ${ }^{2}$ Sebagian besar subyek,
$73,1 \%$ dengan status gizi kurang, $23,1 \%$ gizi buruk $23,1 \%$, dan hanya $3,8 \%$ gizi cukup. Pasien bedah lebih banyak yang mengalami kandidemia dibandingkan bukan bedah. Penelitian tentang kandidemia pada kasus bedah pediatrik sangat jarang. Conde-Rosa $\mathrm{dkk}^{8}$ melaporkan $17,8 \%$ (8/45 pasien) mengalami kandidemia pasca pembedahan abdominal dalam 7 hari perawatan di ruang intensif. 
Terdapat $11,5 \%$ subyek yang menggunakan steroid selama dirawat di PICU dengan lama penggunaan 3-4 hari. Steroid mempunyai efek imunosupresif sehingga memudahkan terjadinya infeksi jamur. Namun begitu, Singhi $\mathrm{dkk}^{6}$ melaporkan (6/45) subyek kandidemia yang mendapatkan steroid dan tidak berhubungan dengan kandidemia. Pada penelitian kami, 96,2\% subyek menggunakan ETT sebagai jalur ke ventilator. Penggunaan ETT akan menimbulkan trauma terbuka dan mengganggu mukosa saluran napas sehingga memudahkan infasi jamur. Penelitian mengenai kejadian kandidemia pada anak yang dirawat di PICU, menyatakan bahwa penggunaan ETT merupakan faktor risiko kandidemia.

Kateter seringkali digunakan pada pasien rawat di PICU, dan menjadi jalan masuk yang mudah bagi patogen, termasuk Candida. Secara umum, pasien dengan kandidemia menggunakan kateter, dan yang paling sering adalah kateter vena sentral atau CVC (central venous catheter). ${ }^{7}$ Penggunaan kateter urin hampir selalu dilakukan di PICU, dan penggunaan kateter urin menimbulkan kerusakan mukosa saluran kemih akibat trauma pemasangan sehingga mempermudah terjadinya kandidemia. ${ }^{9}$ Semua subyek penelitian kami menggunakan kateter vena sentral. Subyek yang menggunakan kateter urin 96,2\%.

Penggunaan antibiotik yang lama berpengaruh terhadap kandidemia karena akan menekan resistensi kolonisasi pada tubuh subyek. Zaoutis $\mathrm{dkk}^{7}$ melaporkan data bahwa penggunaan antibiotik $>15$ hari merupakan faktor risiko kandidemia. Pada penelitian kami, $80,8 \%$ subyek menggunakan antibitotik $>15$ hari.

Data skor PELOD awal masuk PICU merupakan data distribusi tidak normal, kemudian dilakukan transformasi data dan diperoleh data dengan distribusi tetap tidak normal sehingga data karakteristik skor PELOD menggunakan median, dengan median skor PELOD adalah 12. Angka kematian akibat kandidemia mencapai 10\%-14,5\% di antara pasien sepsis. Penyebab kematian ketiga adalah sepsis setelah Staphylococcus coagulase negative dan enterokokus. Hegazi $\mathrm{dkk}^{5}$ melaporkan angka kematian pasien kandidemia 42,4\% (28/66 pasien), sedangkan kami memperoleh angka kematian 34,6\%, dan rerata lama rawat 25,8 hari. Kandidemia memperpanjang masa rawat inap secara signifikan. Brissaud $\mathrm{dkk}^{3}$ melaporkan bahwa lama rawat pasien PICU di rumah sakit anak di Prancis akibat kandidemia sebesar 14-28 hari.
Kejadian kandidemia lebih banyak terdapat pada pasien pasca bedah dan terbanyak adalah pasca bedah abdomen diikuti pasca bedah dada. Hal serupa didapatkan Zaoutis $\mathrm{dkk}^{7}$ yang melaporkan bahwa kejadian kandidemia paling banyak terjadi pada pasien yang sebelumnya mendapatkan prosedur pembedahan. Sebaliknya, kandidemia pada pasien bukan bedah terbanyak terjadi pada syok sepsis. Hasil yang sama didapatkan Singhi $\mathrm{dkk}^{6}$ yang melaporkan bahwa kandidemia terbanyak terjadi pada syok sepsis $43,1 \%$ (28/65 pasien) dibandingkan dengan pasien bukan bedah lainnya (infeksi saluran napas, infeksi sistem saraf, dan infeksi saluran cerna).

Lama penggunaan alat medis invasif pada pasien kandidemia di PICU belum banyak didapatkan. Hegazi $\mathrm{dkk}^{5}$ melaporkan data bahwa subyek penelitiannya yang mengalami kandidemia menggunakan ETT $>7$ hari. Zaoutis $\mathrm{dkk}^{7}$ melaporkan bahwa pasien kandidemia menggunakan kateter vena sentral dan kateter urin lebih dari 7 hari. Kami mendapatkan rerata lama penggunaan ETT adalah 10,0 hari, lama penggunaan vena dalam 15,6 hari, dan rerata penggunaan kateter urin 11,5 hari

Banyak penelitian yang melaporkan penyebab terbanyak kandidemia di PICU adalah Candida albican, diikuti Candida parapsilosis, Candida tropikalis, Candida glabrata, dan Candida krusei. Terdapat tren peningkatan jenis kandida berdasarkan usia, penggunaan alat medis infasif, dan penyakit primer yang mendasari pasien dirawat di PICU walaupun hubungannya belum dapat dibuktikan secara ilmiah. Mac Donald $\mathrm{dkk}^{1}$ melaporkan bahwa peningkatan infeksi Candida parapsilosis terjadi pada pasien yang menggunakan monitor tekanan darah intravaskular. Sementara Jordan $\mathrm{dkk}^{11}$ melaporkan bahwa kejadian Candida albican akan menurun sebanding dengan meningkatnya usia pasien, Candida tropicalis meningkat pada pasien dengan penyakit keganasan atau neutropenia, Candida glabrata meningkat pada pasien setelah pembedahan atau yang terpasang kateter vena sentral. Candida parapsilosis diperoleh karena tranmisi dari paramedis PICU. Pada penelitian kami, penyebab terbanyak adalah Candida parapsilosis dan yang terendah adalah Albican dan Glabrata.

Semua pasien yang dirawat PICU mendapatkan antibiotik. Terdapat kecenderungan penggunaan beberapa jenis antibiotik yang berbeda pada pasien kandidemia. MacDonald $\mathrm{dkk}^{1}$ melaporkan bahwa persentase pasien kandidemia yang menggunakan antibiotik $>4$ yang berbeda sebanyak $50 \%$ sebelum 
mendapatkan anti jamur. Kami memperoleh 34,6\% subyek yang mendapatkan 4 antibiotik.

Kesimpulan pada hasil penelitian kami dijumpai data yang sama dengan negara berkembang lainnya. Kandidemia meningkat pada pasien dengan status gizi kurang, pasien pasacabedah, penggunaan alat medis invasif, dan penggunaan antibiotik labih dari 15 hari.

\section{Daftar pustaka}

1. MacDonald L, Baker C, Chenoweth C.Risk factors for Candidemia in a Children's Hospital. Clin Inf Dis 1998;26:642-5.

2. Giri S, Kindo Aj. A Review of Candida spesies causing blood stream infection. Indian J Med Microbiol 2012;30:270-8.

3. Brissaud O, Guichoux J, Harambat J, Tandonnet O, Zaoutis T. Invasive fungal disease in PICU: epidemiology and risk factors. Ann Intensive Care 2012;2:1-8.

4. Kumar CP, Sundararajan T, Menon T, Venkatadesikalu M. Candidiosis in children with oncohematological studies in Chennai,South India. Jpn J Infect 2005;58:218-21.

5. Hegazi MA, Abdelkader AM, Zaki ME, El-Deek BS.
Characteristics and risk factors of candidemia in pediatric intensive care unit of a tertiary care children's hospital in Egypt. J Infect Dev Ctries 2014;8:624-34.

6. Singhi S, Rao R, Chakrabarti A. Candida colonization and candidemia in pediatric intensive care unit. Pediatr Crit Care Med 2008;9:91-5.

7. Zaoutis T, Priya A, Prasad A. Localio R, Coffin SE, dkk. Risk factors and predictors for candidemia in pediatric intensive care unit patients:Implications for prevention. Clin Infect Dis 2010;51:38-45.

8. Conde-Rosa A,Amador R, Perez-Torres D, Colón E,SánchezRivera C, dkk. Candidemia distribution, associated risk factors, and attributed mortality at a University-Based Medical Center. P R Health Sci J 2010;29:26-9.

9. Zaoutis T. Candidemia in children. Curr Med Res Opin. 2010;26:1761-68.

10. Leteurtre S, Martinot A, Duhamel A. Validation of the paediatric logistic organ dysfunction (PELOD) score: prospective, observational, multicentre study. Lancet 2003;362:192-7.

11. Jordan L, Castila, Casanueva L, Carlos J. C. albican, C. parapsilosis and C. tropicalis invasive infections in the PICU: clinical features, prognosis and mortality. Rev Esp Quimioter 2014;27:56-62. 